\title{
Noticias falsas y la construcción de relatos agnológicos como estrategia política en las movilizaciones de octubre de 2019 en el Ecuador
}

\section{Fake news and the construction of agnological stories as a political strategy in the October 2019 mobilizations in Ecuador}

DOI: https://doi.org/10.29166/tyc.v1i20.2173

Tania Francisca Villalva Salguero

Licenciada en Comunicación Social (Universidad Técnica de Ambato); Especialista Superior en Comunicación para las Empresas (Universidad Andina Simón Bolívar - Sede Ecuador); Magíster en Comunicación (Universidad Andina Simón Bolívar - Sede Ecuador); cursa estudios de doctorado en Comunicación Social (Universidad Austral-Argentina); docente e investigadora de la Carrera de Comunicación Social de la Universidad Politécnica Salesiana; Coordinadora del Grupo de Investigación en Comunicación GIC; integrante del Proyecto Observatorio Universitario de Medios-UPS, sede Quito.

Correo:tvillalva@ups.edu.ec

\section{Pablo Efraín Romero Guayasamín}

Licenciado en Comunicación Social, especialidad investigación (Universidad Central del Ecuador); Especialista Superior en Derechos Humanos (UASB-Sede Ecuador); Diploma Superior en Juventud y Sociedad (FLACSO-Ecuador); Magíster en Comunicación Estratégica (UASB-La Paz); docente e investigador Carrera de Comunicación de la Universidad Politécnica Salesiana; integrante del Grupo de Investigación en Comunicación-GIC, y del proyecto Observatorio Universitario de Medios-UPS, sede Quito.

Correo:promero@ups.edu.ec

\section{Resumen}

La información falsa que circula en las redes sociales es parte de las estrategias de grupos que pretenden desestabilizar a la ciudadanía mediante contenidos errados y malintencionados. El análisis semántico, retórico y sintáctico de 53 noticias que circularon en Facebook, Twitter y WhatsApp durante los 11 días del Paro Nacional en Ecuador, en octubre de 2019, evidencian que la sociedad recibió mensajes que ejercieron una función representativa, expresiva y apelativa. Esta última, desde la emocionalidad, lo que mostró el carácter hostil entre grupos sociales.

Palabras clave: fake news, posverdad, movilización social, agnotología, discurso.

\section{Abstract}

False information posted on social networks is part of the strategies from groups that seek to crumble down citizens through wrong and malicious content. The semantic, rhetorical and syntactic analysis of 53 news that circulated on Facebook, Twitter and WhatsApp throughout the 11 days of the National Strike in Ecuador, in October 2019, shows that the society received messages that deployed a representative, expressive and appealing function. The last one, from emotionality, which showed the hostile character between social groups.

Keywords:fake news, post-truth, social mobilization, agnotology, discourse. 


\section{El punto de inicio}

\section{Gráfico №1: Lenín Moreno, trayectoria y decisiones políticas y económicas}

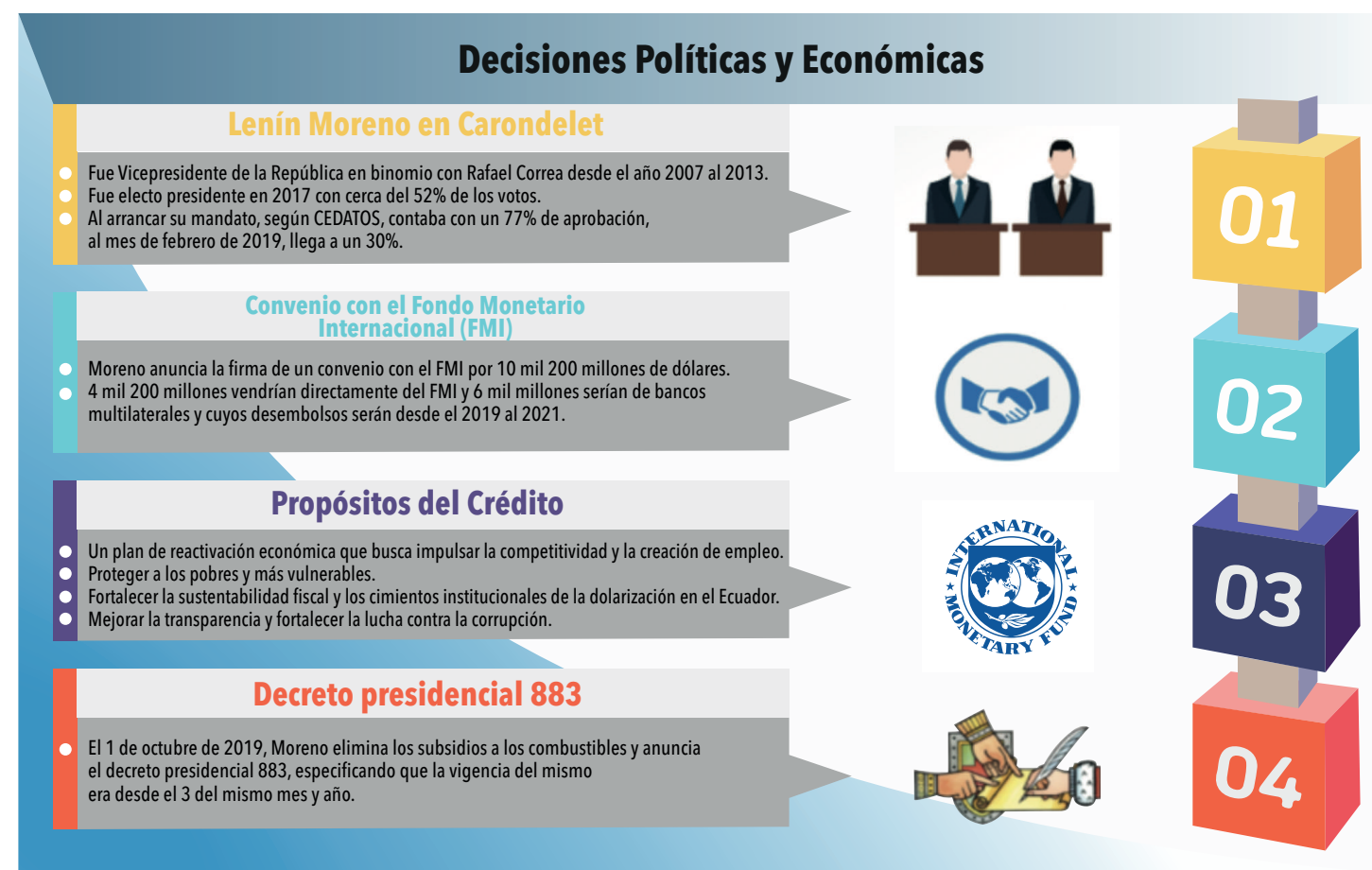

Fuente: información de diario El Universo 2019

Elaborado por: Tania Villalva y Pablo Romero, 2020.

El 01 de octubre de 2019, el presidente de la República del Ecuador, Lenín Moreno, anuncia, en cadena nacional, el Decreto 883, mediante el cual elimina los subsidios a los combustibles, como parte del acuerdo económico con el Fondo Monetario Internacional (FMI); este hecho dio inicio a 11 días de protestas en todo el país y movilizó a miles de personas.

Pillajo (2019) especifica que entre las medidas económicas resaltan:

"la liberación del precio del diésel y la gasolina extra y ecopaís; la baja de sueldo en contratos ocasionales se renueva con $20 \%$ menos de remuneración que afectan todos los habitantes. A esto se suma, las políticas financieras del gobierno sobre la nueva emisión de bonos soberanos, por un valor total de 2.000 millones de dólares. Con esto, desde mayo de 2017, se han colocado 11.675,74 millones en nueva deuda pública. El endeudamiento público total pasa de 55.00o millones a más de 57.000 millones" (pág. 148).

El FMI establece los parámetros para el desembolso, lo que condiciona la acción del Gobierno, pues el anuncio desequilibra a las familias y afecta el estilo de vida de los ecuatorianos. De ahí que las movilizaciones estuvieron lideradas por 149 organizaciones indígenas representa- 
das por la Conaie ${ }^{1}$, Fenocin $^{2}$, Ecuarunari $^{3}$, Feine $^{4}$, Conaice $^{5}$ y Confeniae ${ }^{6}$ hasta lograr la derogatoria del decreto.

Quito, la capital del Ecuador, fue el escenario principal de la lucha social. Los puntos de encuentro fueron la Casa de la Cultura y el parque El Arbolito, sitios representativos de resistencia, acogida y espacio ceremonial. Además, se sumaron como zona de paz y acogida humanitaria las universidades que geográficamente estuvieron cercanas a los acontecimientos para brindar descanso, alimento y atención médica.

En estas jornadas de protesta, la sociedad ecuatoriana fue testigo de la capacidad de participación ciudadana y de una combinación entre actores sociales del campo y de las ciudades (Pillajo, 2019) en la lucha contra políticas inequitativas. Los

\section{Gráfico N²: Cronología de los hechos durante el Paro Nacional}

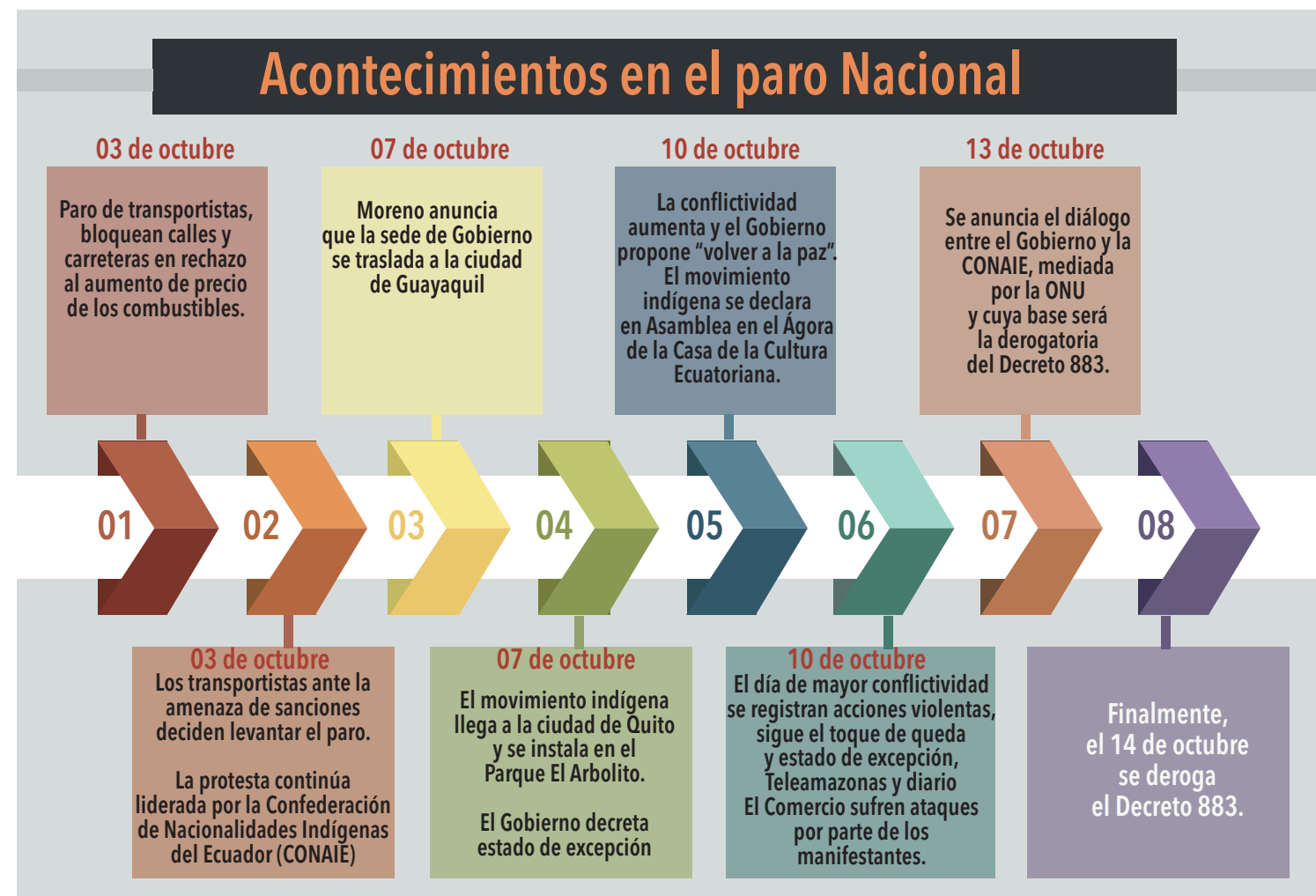

Fuente: Información presentada en El Universo 2019

Elaborado por: Tania Villalva y Pablo Romero, 2020.

\footnotetext{
Confederación de Nacionalidades Indígenas del Ecuador

Federación Ecuatoriana de Organizaciones Campesinas, Indígenas y Negras

Confederación de Pueblos de la Nacionalidad Kichwa del Ecuador

Federación Ecuatoriana de Indígenas Evangélicos

Confederación Nacional y Pueblos Indígenas de la Costa Ecuatoriana

Confederación de las Nacionalidades Indígenas de la Amazonia Ecuatoriana
} 
actos de violencia reflejan la catarsis que la ciudadanía vivió en los 11 días de protestas y la inoportuna y lenta respuesta de un gobierno con muy poca capacidad de análisis y reflexión en la toma de decisiones. (Véase Gráfico No. 2)

El discurso presentado por Jaime Vargas y Leonidas Iza, presidente de la CONAIE, y de la ECUARUNARI, respectivamente, tuvo una postura radical en contra de las medidas. Su poder de convocatoria a sectores campesinos e indígenas y otros colectivos sociales se evidenció en estas últimas protestas.

De acuerdo con José Antonio Figueroa (2019), el movimiento popular se propuso recuperar la soberanía en el manejo de los asuntos económicos; por ello dirigió la principal crítica a los asuntos financieros planteados por Moreno; sin embargo, las protestas evidenciaron otros frentes de inconformidad, como el papel arbitrario en el manejo de la información por parte de los medios de comunicación, que mostraron un ambiente favorable a la consolidación del capitalismo.

"La falta de credibilidad de los medios masivos de comunicación y la manipulación sobre los hechos de la protesta social lograron consolidar un cerco mediato desde una la política informativa y comunicativa por parte del gobierno ecuatoriano en esos días de protesta. Eso conllevó, a que los medios de comunicación comunitaria y alternativa jugaran un papel relevante en la difusión de información, así como el uso de redes sociales, que protagonizaron otros accesos a la información" (Pillajo, 2019. pág. 153).

El poder de convocatoria mediante las redes sociales se evidenció en la noche del "cacelorazo" el 12 de octubre de 2019.
Aunque su propósito no estaba definido, ni la fuente de convocatoria, la mayoría de los barrios en la capital protestaron desde sus espacios. Muchos consideraban que la medida era para desafiar el toque de queda; otros lo hicieron como un llamado a la paz; y una parte por la crisis que el país vivía en esos momentos. De todos modos, la conectividad mediática rebasó la información tradicional y la resistencia se hizo desde la red.

"El paro nacional del Ecuador muestra los límites de la pos-verdad" (Figueroa, 2019. Pág 180); la información que circuló en las redes sociales desmanteló los intereses estructurales y políticos del Gobierno y evidenció una sociedad que construye, destruye y se construye desde la red; pues el discurso sobre la lucha contra la corrupción se vio articulado en ciento de posteos que sugerían levantarse y unirse a las protestas.

\section{Fake News y agnología}

El término posverdad fue declarado en 2016 como la palabra internacional del año por la Universidad de Oxford. Se define como las "circunstancias en que los hechos objetivos influyen menos en la formación de la opinión pública que las referencias a emociones y a creencias personales" (Fernández, 2017, p.67-68). Por lo tanto, es una falsedad que continúa siendo aceptada a sabiendas de que es una falsedad, pero reforzada como creencia o como hecho compartido en una sociedad (Amón, 2016).

En este sentido, se trata de la formación deliberada de una ignorancia social, lo que Proctor (2008) denomina agnotología, una manera de producir ignorancia de manera deliberada. De 
acuerdo con Estela Morales (2018) la posverdad es el resultado de un modo planificado y deliberado de actuar para beneficiarse de los efectos de la misma. La posverdad procura fijarse mentalmente y actuar en contextos y espacios acotados; opera en realidades específicas en las que el discurso se delimita, perfecciona y escenifica junto con las emociones (p. 25).

El alcance que ha adquirido la posverdad se debe, sobre todo, a las actuales condiciones de producción y circulación de la información a través de internet y de manera particular de las redes sociales o, como lo señala Clavero (2018):

\footnotetext{
quienes antes eran categorizados como audiencia, hoy son nodos de generación y distribución de contenidos e información relevante para sus contactos. Para comprender la posverdad, resulta pertinente plantearse las condiciones actuales de producción de las noticias, que ya no están en manos solo de profesionales, sino también de cualquier persona, incluso de una machine (p.178).
}

De tal manera que la forma tradicional de consumo de información y noticias ha sido desplazada por las redes sociales que han pasado a ser hegemónicas. Para enero de 2019, según datos del Global Digital, elaborado por We Are Social y Hootsuiteen, en Ecuador el uso de internet alcanzó un 79\%, es decir, 13.4 millones de usuarios, de los cuales 12 millones navegaron en alguna red social, y el dispositivo preferido fue el teléfono celular, con un total de 11 millones de usuarios.

En este punto es importante señalar que existen muchos filtros en internet que impiden que puntos de vista en conflicto con los nuestros sean de nuestro conocimiento. De esa manera nos aíslan en nuestra propia burbuja de información. Eli Pariser (2017) los denomina filtros burbuja, que obstaculizan el acceso a la información que puede contradecir o ampliar nuestra visión del mundo, de tal suerte que la exposición a un limitado contenido informativo hace que la gente crea que sus ideas coinciden con la visión dominante.

\begin{abstract}
De hecho, Google rastrea entre más de 57 variables (por ejemplo, marca del ordenador desde el que se accede, ubicación, software utilizado, etc.) para determinar los resultados de búsqueda que serán más relevantes para cada persona. Con todos estos datos, personaliza el contenido que muestra a cada usuario. A los filtros burbuja se unen las cámaras de resonancia (echo chambers), en las que la información, las ideas o creencias son amplificadas por transmisión y repetición en un sistema cerrado donde las visiones diferentes o alternativas se descartan o se representan de forma minoritaria. Así, los ciudadanos terminan consumiendo noticias ajustadas a su modo de pensar (Fernández 2017. p. 68).
\end{abstract}

Pero este contenido personalizado y su respectiva viralización es el resultado de algoritmos, que deciden el orden de las noticias y determinan las tendencias, sin necesariamente establecer que la información sea verdadera o falsa.

De ahí que, a decir de Ramoneda, citada por Morales (2018) "los modos y la capacidad de propagación de los mensajes (entre el monopolio de unos pocos y la jungla de las redes sociales) convierten en completamente ineficaces los viejos protocolos de la razón crítica y de la evaluación de la verdad de los mensajes, siendo el periodismo la primera víctima de ello" (p. 16 y 17).

La emocionalidad va a prevalecer, así como la información que congenia con ciertas posturas ideológicas. En Facebook importa más el usuario que comparte la noticias que la fuente de la misma, según 
dice un estudio experimental de Media Insight Project, en 2017. "Es decir, que los ciudadanos confíen en la persona que comparte la noticia es más importante que quién produce la noticia o incluso si el artículo ha sido escrito por una organización de medios real” (Fernández 2017, p 71).

Para Morales (2018) las mentiras que producen ignorancia de manera deliberada en las redes sociales son parte de una estratégica política que tiene como función central la comunicación y no la expresión del pensamiento. De acuerdo con Mounin (1983), esta práctica va de la función representativa (representación del estado de cosas, objeto del diálogo), a una expresiva (ofrece una gran cantidad de síntomas de sí mismo) para arribar a una apelativa (provocar en el interlocutor ciertos sentimientos específicos).

Por lo tanto, la posverdad crea un campo fértil desde lo emotivo o lo sentimental para conspirar, crear malestar, provocar el recelo o la hostilidad de o entre grupos sociales en el marco de una estrategia política de actores que buscan o ejercen el poder. para que la posverdad rinda frutos (...) es necesario contar con el acceso a medios y redes de comunicación, contextos sociales sensibles a los mensajes agnotológicos, estrategas y operadores políticos, además de los comunicadores y los recursos económicos asociados a la ejecución de prácticas de posverdad. Por sus consecuencias, es vital continuar con el análisis de la información como recurso estratégico de guerra política y sus consecuencias para la vida pública que es consustancial para la democracia (Morales, 2018. p 26).

\section{La apuesta metodológica y los hallazgos}

La inmediatez de la información hace difícil el reconocimiento de una noticia falsa; pese a ello, medios de comunicación y periodistas se concentran en la identificación de las fake news que circulan por las redes sociales. Pese al esfuerzo, con alto grado de éxito, el problema no logra ser resuelto. Conroy, N. J.; Rubin, V. L.; Chen, Y. (2012), presentan dos enfoques que permiten acercarse a este problema. El enfoque lingüístico, que determina el análisis de la sintaxis, la semántica y la estructura retórica; y el enfo-

\section{Gráfico № 3: Descripción de la matriz de análisis utilizada para el levantamiento de la información}

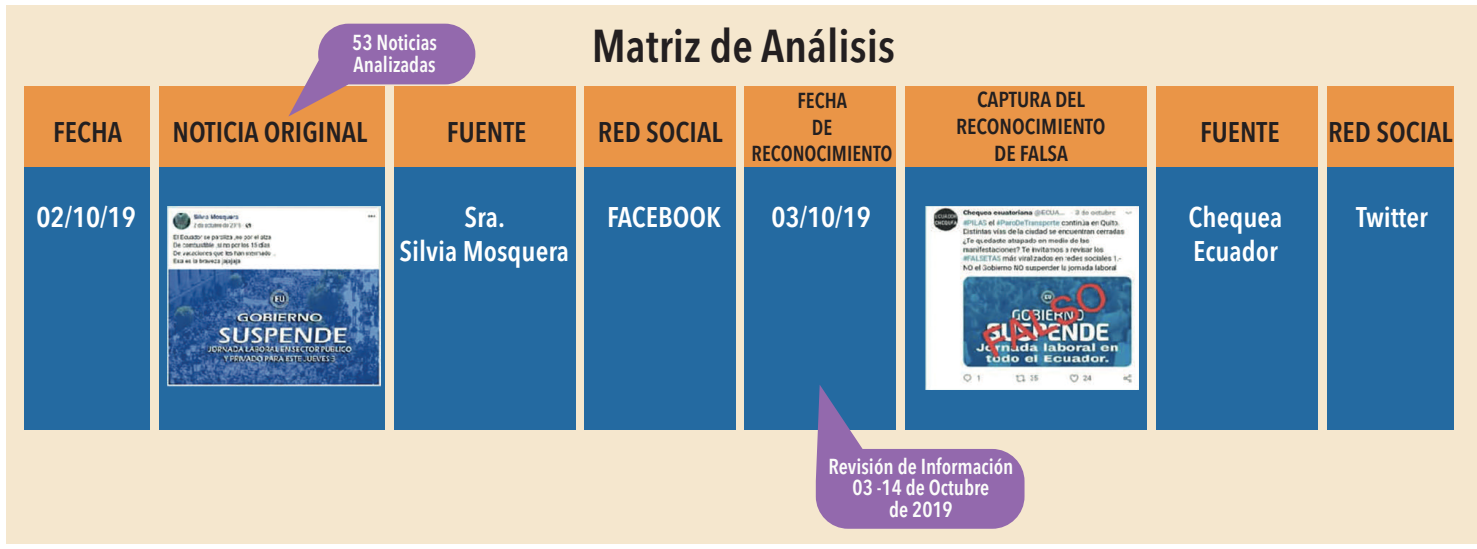

Fuente: datos de investigación levantada por los autores.

Elaborado por: Tania Villalva y Pablo Romero, 2020. 
que de red que visibiliza los datos vinculados y el comportamiento de estos en la red.

Las protestas de octubre en Ecuador tuvieron varios matices en el manejo de la información y, sobre todo, un alto grado de circulación de noticias falsas. Para este estudio se ha logrado consolidar una muestra de 53 noticias que circularon en Facebook, Twitter y WhatsApp, en un periodo de 11 días, del 3 al 14 de octubre de 2019. Para el análisis de la red de información se trabajó desde la técnica de representación de datos con la creación de grupos de palabras significativas, la frecuencia de las fake news, la temporalidad y vigencia de la información errada en la web.

\section{(Véase Gráfico $\mathrm{N}^{o} 3$ ).}

Desde la técnica de comportamiento de red, se logra evidenciar que la información errada proviene de perfiles falsos, que manejan, como foto de perfil, elementos gráficos afines al expresidente ecuatoriano, Rafael Correa. También usan otros identificativos de personajes de caricaturas o avatares que representan el tema político. Esto permite evidenciar que son cuentas poco confiables, pues su historial de publicaciones no es frecuente y la fecha de creación es reciente.

Sin embargo, existen cuentas que replican la información sin corroborar la veracidad de la misma. Esto provoca que el contenido se masifique. En promedio, la información tarda un día en ser identificada como fake news y publicada para evidenciar la intención descontextualizada.

\section{(Véase Gráfico No. 4).}

Entre las cuentas no oficiales de Facebook, Twitter y Whatsapp más utiliza-

\section{Gráfico $\mathrm{N}^{\circ}$ 4: Tiempo estimado en identificar una noticia falsa}

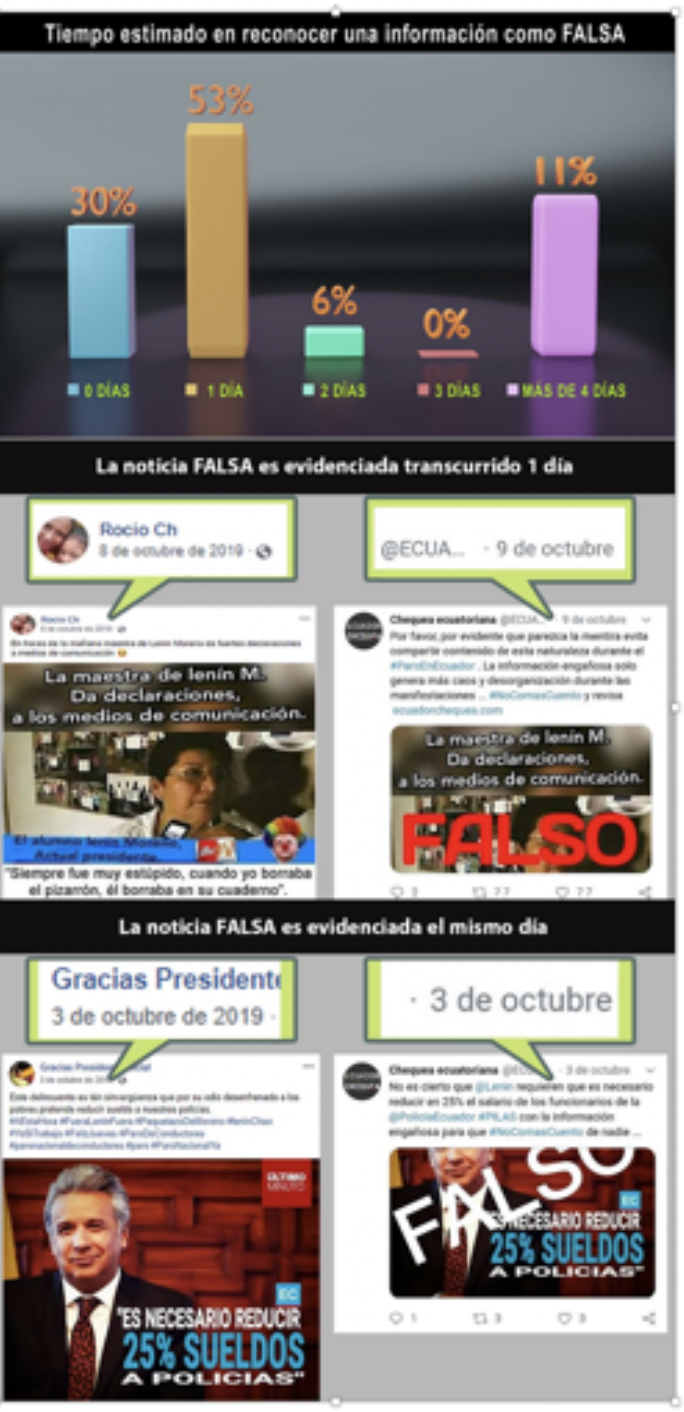

Fuente: datos de investigación levantada por los autores.

Elaborado por: Tania Villalva y Pablo Romero, 2020.

das están: Gracias Presidente Oficial, Presidente ecuatorianos, Desborde Ecuador, Ecuatorianos por siempre, Al tanto, El Camaleón Bipolar, MST - Junior, Revolución 2021-Madrid, Patriota Ecuador; que evidencian una postura 
contraria a la política actual del Gobierno de Lenín Moreno.

De la misma manera, el contenido informativo de las publicaciones carecía de datos concretos y se presentaba como superficial. Esto reveló que la información fue engañosa y contenía ambigüedades en el lenguaje, pues los recursos utilizados para la exposición de la información fue la ironía, el humor y los insultos. Para esto último se trabajó desde la sintaxis de estructura profunda (Adrados, F. R. 1976), mediante el reconocimiento de oraciones compuestas por sujeto, verbo y predicado.

En este sentido, el análisis semántico (Adrados, F. R. 1976) permitió trabajar en la identificación de incoherencias desde el reconocimiento del contexto y la posibilidad de falsedad. El análisis de la retórica permitió establecer esquemas y supuestos que son frecuentes en las noticias falsas (Blázquez-Ochando, M. 2018). (Gráfico No. 5)

Para determinar la veracidad de la información se debe siempre observar la fuente, determinar si se trata de especialistas, analistas, investigadores o expertos en el tema; considerar qué tipo de infor-

\section{Gráfico $N^{0} 5$ \\ Representación de las cuentas utilizadas para la emisión de contenido falso.}

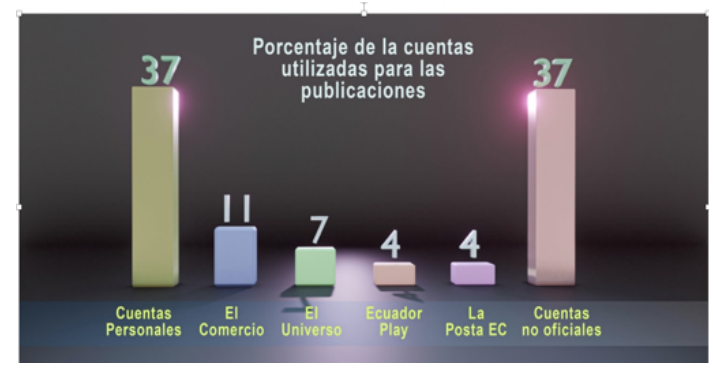

Fuente: Datos de la investigación levantada por los autores.

Elaborado por: Tania Villalva y Pablo Romero, 2020. mación, datos o anexos proporciona; y sobre todo contrastar la información desde una gama de fuentes confiables, identificadas por el receptor. Describirlo es más fácil que hacerlo, pues la inmediatez de la información que transita por las redes sociales termina siendo abrumadora, y la tarea de verificación se vuelve algo compleja y lenta (Blázquez-Ochando, M. 2018).

Una de las mejores precauciones para comprobar la fiabilidad de la información que circula en la web es cuantificar cuántas referencias tiene, o cuántas fuentes citadas presenta; determinar si la información presenta datos estadísticos debidamente citados; y si la noticia responde a un hecho coyuntural. Sin embargo ¿qué complicaciones presenta la sociedad en general cuando recibe la información poco tratada o investigada?, ¿cuándo una noticia es legítima?, ¿es posible identificar una noticia falsa con inmediatez y veracidad?

$\mathrm{Al}$ analizar la información en la red, podemos realizar un escrutinio de datos que evidencie la fecha de creación de la cuenta, número de seguidores, movimiento del historial de las publicaciones, y especificar si es una cuenta oficial. De esta manera se puede asegurar en buena medida la veracidad del contenido.

Otro factor que puede intervenir en la publicación de noticias falsas es la falta de normalización en las noticias. Esto puede ser debido, en parte, a una relajación de los deberes periodísticos, que no son responsabilidad de la Documentación. También puede estar propiciado por el hecho de que las redes sociales y las aplicaciones de mensajería han permitido que cualquier persona se convierta en periodista, sin necesidad de formación específica, en lo que se conoce como "Periodismo ciudadano" (Espiritusanto, O.; Rodríguez, P. G. 2011. Citado en Blázquez-Ochando, M. 2018, pág: 8). 


\section{Gráfico $N^{\circ} 6$ \\ Nube de las palabras con mayor repetición \\ en el contenido de la información falsa}

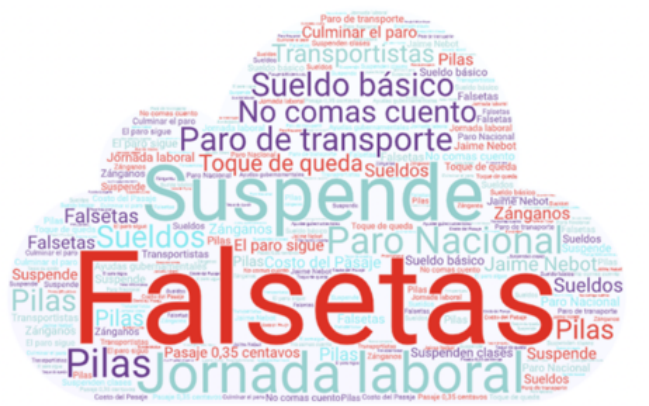

Fuente: Datos de la investigación levantada por los autores. Elaborado por: Tania Villalva y Pablo Romero, 2020.

Sin embargo, entender las fake news como agnotología, es decir, la formación deliberada de la ignorancia social $y$, en este caso en particular, con fines políticos, requiere evidenciar la narrativa que se busca construir a partir de la "viralización" de noticias falsas (una discusión que ha surgido a propósito de las llamadas "noticias falsas", es que no se las debe llamar como tal, sino como lo que realmente son: mentiras; sin embargo esta discusión no es motivo de abordaje en este artículo) que apelan a la emocionalidad e irracionalidad, como ocurrió en la crisis social que se vivió en el Ecuador y que, a continuación, presentamos de forma cronológica.

En el contexto del anuncio del paro de transporte y de las movilizaciones en rechazo al decreto 883 de eliminación de los subsidios a los combustibles, las primeras noticias falsas que circularon el 2 de octubre fueron: "Gobierno suspende jornada laboral para este jueves"; "Los salarios se pagarán el 5 de cada mes (a mes siguiente)"; "Gobierno modifica el sueldo básico a 280 usd".
El 3 de octubre, los transportistas del servicio público se declaran en paro y bloquean las principales vías en ciudades y varias carreteras a lo largo de país. El Gobierno responde con un decreto de Estado de Excepción y, en este contexto, las fake news que invaden las redes sociales son: "Gobierno decreta toque de queda"; "Se reducirá sueldo a policías en un 25\%"; "Nebot huye del país"; "Se incrementa costo del pasaje a 0.40 usd"; "Rocío de Moreno abandona el país".

Para el 5 de octubre, los transportistas, ante la amenaza de sanciones, deciden levantar el paro, sin embargo, la protesta continúa liderada por la Confederación de Nacionalidades Indígenas del Ecuador (Conaie), e incluye al Frente Unitario de Trabajadores (FUT), estudiantes y activistas, entre otros sectores. De ahí que la información falsa que circulará indicará lo siguiente: "La Ministra de Gobierno, María Paula Romo, señala que los transportistas decidieron levantar el paro y que en las calles solo quedan unos zánganos"; "Se elimina el subsidio del gas"; "Se suspenden clases desde el lunes"; "El gobierno nacional entrega bonos a venezolanos"; "Indígenas llegan al Centro Histórico"; "Líder de la Conaie exige liberación de Jorge Glas"; "Declaraciones del presidente Moreno: ningún indio miserable, ni los delincuentes que están manifestando en las calles pueden vencer a la democracia".

El 7 de octubre el presidente Moreno anuncia que la sede de Gobierno se traslada a la ciudad de Guayaquil, pues declara que es víctima de un intento de golpe de Estado promovido por el expresidente Correa, por lo que las noticias falsas se centrarán en lo siguiente: "Vicepresidente pide a Lenín Moreno dar un paso al costado por el bien del país"; "Moreno se refugia en base militar de Taura"; "Correa 
anuncia que llegará a Guayaquil en las próximas horas"; "Militares hacen un llamado a soldados indicando que es hora de sacar a Moreno"; "Se emiten boletas de captura para la cúpula correísta”.

Entre el 9 y el 11 de octubre, el presidente Moreno regresa a Quito y anuncia que se está llevando adelante un proceso de diálogo con el movimiento indígena, pese a la permanente denuncia de la fuerte represión policial a los manifestantes. En este marco la información falsa que circulará es: "Militantes de Revolución Ciudadana se toman en Consulado de Ecuador en Madrid"; "Maestra de Lenín: siempre fue muy estúpido, cuándo yo borraba el pizarrón, el borraba en su cuaderno"; "Rocío de Moreno tramita asilo político en Suiza para ella y su esposo"; "Alta cúpula militar de las FFAA pide renuncia al presidente"; "Jefe de operaciones de la Policía Nacional señala que se autoriza la utilización de granadas en contra de los manifestantes"; "Gobierno decreta eliminación de los feriados de octubre y noviembre"; "Soldados de élite de la Amazonía se dirigen a Quito en apoyo a la movilización indígena”.

El 12 de octubre será el día de mayor conflictividad; varios puntos de Quito registran, de manera simultánea, acciones violentas pese a regir "un toque de queda” y Estado de Excepción con movilización militar. Varios medios de comunicación son atacados por manifestantes y el edificio de la Contraloría General del Estado es incendiado. Un estado de zozobra invade a los habitantes de Quito y las fake news que aparecen este día señalan lo siguiente: "Policía Nacional hace declaraciones indicando que están cansados de sofocar las manifestaciones y pide al presidente Moreno que solucione las movilizaciones sino le van a quitar el apoyo"; "FFAA desconocen al presidente Lenín Moreno como primer mandatario del Ecuador"; "Manifestantes entran al Palacio de Carondelet".

Como se puede evidenciar, hay un relato que construyen las noticias falsas; un relato que corre de forma paralela y articulada a los acontecimientos coyunturales. La intención es apelar a la emotividad y buscar una reacción por parte de los consumidores de esta información como parte de una estrategia política que, aunque hasta ahora no tiene un origen muy claro, sí evidencia la finalidad de abonar al caos y a la crisis social y política en el contexto de las movilizaciones de octubre de 2019.

\section{Conclusiones}

La manera en que accedemos a la información ha cambiado radicalmente en los últimos años. La prensa y los informativos de televisión pierden audiencia, la mayor parte de la información circula a través de las redes sociales, especialmente Facebook, seguido de Youtube y Twitter, espacios privilegiados de circulación de fake news.

Ya en cuanto a la información analizada, hay un paralelismo entre los acontecimientos que se suscitan en el marco de las movilizaciones de rechazo al decreto 883 , que elimina los subsidios a los combustibles, y las noticias falsas que circulan en las redes sociales. Esto ocurre mediante una sincronía que evidencia un interés por generar ignorancia de manera deliberada y movilizar la emocionalidad de la población en contra del gobierno.

La casi totalidad de las noticias falsas (48 de 53 noticias falsas) tiene una narrativa cuya "víctima" es el gobierno nacional, al que se muestra como incapaz 
u objeto de burla, que toma medidas impopulares, que no tiene el apoyo de Policía y Fuerzas Armadas y que prepara su abandono del poder y/o del país.

Es permanente la apelación que se hace a la Policía y a las Fuerzas Armadas, al indicar que estos actores han quitado el apoyo al presidente Moreno o que están conminando al gobierno a dar un paso al costado y ceder la Presidencia.

En el marco de las declaraciones del gobierno de avanzar en el diálogo con el movimiento indígena, circulan en las redes sociales noticias falsas que buscan poner en mayor contradicción a estos actores (Moreno dice que ningún indio miserable, ni los delincuentes que están manifestando en las calles pueden vencer a la democracia; mientras que Líder de la Conaie exige la liberación de Jorge Glas), lo que hace presumir que el interés de cir- cular estas fake news es el de que este proceso de diálogo no prospere.

Otro de los actores que aparecen en las fake news, pero desde una perspectiva que actúan con iniciativa (Militantes de Revolución Ciudadana se toman consulado de Ecuador en España) y luego en calidad de víctimas (Se pone boleta de captura para dirigentes de Revolución ciudadana), es el sector vinculado con el ex presidente Correa.

Una forma de apelar a la emocionalidad y buscar que la población se indigne frente al gobierno, es abordar temas sensibles como la reducción de salarios a la población en general, y luego a los servidores policiales, o señalar que el gobierno entrega bonos a la población venezolana que está en el Ecuador, así como la eliminación del subsidio del gas o la subida de pasajes. 


\section{Bibliografía}

Adrados, F. R. (1976). Reflexiones sobre semántica, sintaxis y estructura profunda. Revista española de lingüística, 6 (1), $1-26$.

Amón Rubén, 'Posverdad', palabra del año, El País, España. https://elpais.com/internacional/2016/11/16/actualidad/ 1479316268_308549.html

Blázquez-0chando, M. (2018). El problema de las noticias falsas: detección y contramedidas.

Conroy, M., Feezell, J. T., \& Guerrero, M. (2012). Facebook and political engagement: A study of online political group membership and offline political engagement. Computers in Human behavior, 28(5), 1535-1546.

Eli Pariser: Fake news, los filtros burbuja y la batalla por la verdad, conferencia en el ciclo \#TechSociety, celebrada el 19 de junio de 2017 en Espacio Fundación Telefónica. https://www.fundaciontelefonica.com/cultura-digital/conferencias/eli-pariser/

Estela Morales Campos, Coord. (2018) La posverdad y las noticias falsas: el uso ético de la información, México: UNAM, Instituto de Investigaciones Bibliotecológicas y de la Información.

Figueroa, J. A. (2019). El Ecuador: del posmodernismo a la lucha por la hegemonía popular. BORDES, (14), 177-181. Juan Alberto Clavero (2018) Posverdad y exposición selectiva a fake news. Algunos ejemplos concretos de Argentina, en Contratexto n.o 29, enero-junio 2018, pp. 167-180, Lima: Universidad de Lima.

Mediática, en revista Nueva Sociedad No 269, mayo-junio de 2017, Buenos Aires: Fundación Friedrich Ebert (FES). Nuria Fernández-García (2017) Fake news: una oportunidad para la alfabetización.

Pillajo, F. S. Resistencia y lucha social indígena en los Andes ecuatorianos: Paro Nacional 2019.

Ramos Alejandro (2018), Información Líquida en la era de la posverdad, en Revista General de Información y Documentación, México:UNAM.

Robert Proctor (2008) Agnotology: The Making and Unmaking of Ignorance. Stanford: Stanford University Press. 